The IJA is a peer-reviewed open-access, electronic journal, freely available without charge to users

\title{
Characterization, functional analysis and antibacterial activities of theromacin from the Akoya pearl oyster Pinctada fucata
}

\author{
Hua-Yang Guo 1,2,3,4, Bo Liu'1,2, Jing-Wen Yang 1,2, Shi-Gui Jiang1,2,3,4, \\ Dian-Chang Zhang $1,2,3,4 *$
}

\author{
${ }^{1}$ Key Laboratory of South China Sea Fishery Resources Exploitation and Utilization, \\ Ministry of Agriculture and Rural Affairs; South China Sea Fisheries Research Institute, \\ Chinese Academy of Fishery Sciences, 510300, Guangzhou, Guangdong Province, China \\ 2 Tropical Aquaculture Research and Development Center, South China Sea Fisheries \\ Research Institute, Chinese Academy of Fishery Sciences, 572018, Sanya, Hainan \\ Province, China \\ ${ }^{3}$ Guangdong Provincial Engineer Technology Research Center of Marine Biological Seed \\ Industry, Guangzhou, Guangdong Province, China \\ ${ }^{4}$ Guangdong Provincial Key Laboratory of Fishery Ecology and Environment, Guangzhou, \\ Guangdong Province, China
}

Key words: Pinctada fucata, antimicrobial peptides, theromacin, antibacterial activities

\begin{abstract}
The Akoya Pearl oyster Pinctada fucata is distributed over the coastal area of South China and is the most popular farming shellfish for seawater pearl production. Antimicrobial peptides (AMPs) could inhibit or kill pathogenic microorganisms. Theromacin has been proven to be an antimicrobial peptide, which plays an essential role in the body's immune system. The AMP gene to be identified was encoding theromacin in the pearl oyster Pinctada fucata (PoAP). The full-length PoAP cDNA contains 522 bp and consists of a $5^{\prime}$-UTR of $6 \mathrm{bp}$, an unusually long 3'-UTR of $749 \mathrm{bp}$, and an open reading frame (ORF) of 375 bp that encodes a 124 amino acid peptide with a molecular weight of $13.67 \mathrm{kDa}$ and the theoretical isoelectric point of 9.25. Homology analysis of the deduced amino acid sequence of the PoAP with other known theromacin sequences by MatGAT software revealed that the POAP shared $29.0 \%-46.8 \%$ similarity to the other known theromacin sequences. Signal P-N program showed that PoAP contains 33 amino acid signal peptides and a mature peptide located at amino acids 34-124; the mature peptide contains 12 cysteine residues and 13 alkaline amino acid residues with a molecular weight of 13.67 $\mathrm{kDa}$ and the theoretical isoelectric point of 9.25. The tempered program suggests that PoAP is a membrane protein with one transmembrane helix between amino acids 13 and 34 . The PoAP gene was linked into prokaryotic vector $\mathrm{DET}-32 \mathrm{a}$, and the PoAP fusion protein with $31 \mathrm{kDa}$ molecular mass was successfully expressed in Escherichia coli BL21. Using His-Bind Purification Kit Protocol purifies the antimicrobial peptides recombinant protein and compares the bacteriolysis effect on Gram-positive and Gram-negative bacteria using the purified protein. The results show that PoAP proteins had a bacteriolysis effect on the Gram-negative bacteria but on Gram-positive organisms. The antibacterial peptides theromacin seem to play a crucial antibacterial function in the immune responses of pearl oysters.
\end{abstract}

\footnotetext{
* Corresponding author. Dr. Dian C. Zhang. 231 Xingang Road West, Haizhu District, Guangzhou City, Guangdong Province,
} 510300, PR China. E-mail address: zhangdch@scsfri.ac.cn ; Phone: +86 02089108316; fax: +86 02089022702 


\section{Introduction}

Mollusks have only non-specific immune systems and no specific immune systems. Therefore, the immune system of mollusks could be divided into cellular immunity and humoral immunity (Loker et al., 2010). In addition to cellular immunity, humoral immunity is an essential part of the shellfish immune system. The humoral immunity of shellfish depends on immune factors such as agglutinin, opsin, and antimicrobial peptides, which directly or indirectly regulate the immune function of blood cells, participate in the immune defense process, and play an important role in the entire immune defense mechanism (Wang et al., 2013a; Wang et al., 2013b).

Antimicrobial peptides (AMPs) are defensive polypeptide active substances against the pathogenic effects of exogenous pathogens. It is an important component of the innate immunity of organisms. Antibacterial peptides widely exist in vertebrates and invertebrates. They have inhibitory or killing effects on pathogenic microorganisms such as fungi and bacteria, which are often referred to as the "second defense system."

At present, four species of Macin family members have been discovered, namely theromaicn (Tasiemski et al., 2004), hyramacin (Jung et al., 2009), mytimacin (Marco et al., 2012), and neuromacin (Sascha et al., 2012). Among them, theromaicn (TM) is an antimicrobial peptide that has been proven to have antimicrobial effects and plays a vital role in the body's immune system. It has been reported in species such as Theromyzon tessulatum (Tasiemski et al., 2004), Hirudo medicinalis (Schikorski et al., 2008), and Hyriopsis cumingii (Xu et al., 2010).

Pearl oyster (Pinctada fucata) is one of the main species cultivated in seawater pearls. In recent years, severe mortality occurred in the cultivation of $P$. fucata by severe environmental pollution and disease outbreaks. There are few studies on the antimicrobial peptide Theromacin gene of shellfish, but the role of theromacin is still unknown in innate immunity. Therefore, to further understand the mechanism of the shellfish theromacin gene in the innate immune defense, it must be separated more shellfish theromacin gene. In this study, we found that an EST (pmpca0_000958) has a high similarity with the antimicrobial peptide theromacin gene of Aplysia californica (ABF21076.1) and $H$. cumingii (ADK94899) through EST sequence analysis. Based on this, we cloned the antimicrobial peptide theromacin gene of $P$. fucata through RACE technology and recombined it in vitro by constructing a prokaryotic expression vector of the gene. At the same time, the antibacterial peptide was purified, which brought about investigations on their antibacterial effects.

\section{Pearl oyster and immune challenge}

\section{Materials and Methods}

Pearl oyster $P$. fucata (bodyweight $18.2-22.5 \mathrm{~g}$ ) was obtained from the pearl oyster culture base of the South China Sea Fisheries Research Institute in Xincun village, Hainan province, China, maintained at $25-27^{\circ} \mathrm{C}$ in tanks with recirculating seawater for one week before the experiment. In the whole experiment process, the pearl oyster was fed twice daily on Tetraselmis suecica and Isochrysis galbana. Pearl oysters were injected into the adductor muscle with $100 \mu \mathrm{l}$ of Phosphate Buffered Saline (PBS: $137 \mathrm{mM} \mathrm{NaCl}, 2.7 \mathrm{mM}$ $\mathrm{KCl}, 10 \mathrm{mM} \mathrm{Na} 2 \mathrm{HPO} 4,2 \mathrm{mM} \mathrm{KH} 2 \mathrm{PO} 4, \mathrm{pH} 7.4$ ) as the control group. The bacterial challenge group was performed by injecting $100 \mu \mathrm{l}$ of Vibro alginolyticus resuspended in PBS to $\mathrm{OD} 600=0.4(1 \mathrm{OD}=5 \times 108$ bacteria $\mathrm{ml}-1)$ into the adductor muscles of each pearl oyster. At each time point $(0,2,4,8$, and 12), the intestine was collected from the control and bacterial challenge groups and stored in liquid nitrogen until used. For tissue distribution analysis, unchallenged pearl oyster's digestive gland, gills, mantle and intestine, and gonad were collected as an unchallenged group and stored in liquid nitrogen until used. Pearl oysters of each group were divided into three replicates with equal amounts and fed in three tanks. Five pearl oysters were randomly sampled from each group at each time point and mixed corresponding tissues with equal amounts as one sample. 


\section{RNA extraction and CDNA preparation}

CDNA library was constructed from the whole body of a pearl oyster challenged by $V$. alginolyticus, using the ZAP-cDNA synthesis kit and ZAP-CDNA GigapackIII Gold cloning kit (Stratagene). BLAST analysis of all expressed sequence tag (EST) sequences revealed that an EST of 542 bp (EST no: Pmpca0_000958) was homologous to the theromacin of Aplysia californica (ABF21076.1) and Hyriopsis cumingii (ADK94899). Based on the sequence of this EST, the corresponding colony was picked up and resequenced to obtain the complete sequence of the theromacin.

\section{Sequence analysis of PoAP}

PoAP amino acid sequence was predicted using DNATool version 6.0 software. The percentage of similarity and identity of the known theromacin sequences was calculated using the MatGAT program (Campanella et al., 2003) with default parameters. The protein domain was predicted with the simple modular architecture research tool (SMART) program (Letunic et al., 2006). The protein sequence of theromacin was compared to its counterpart sequences currently available in GenBank using the BLAST program (Altschul et al., 1997) (http://www.ncbi.nlm.nih.gov). We have done multiple alignments of theromacin with the ClustalW program (http://www.ebi.ac.uk/clustalw/). We constructed the phylogenetic tree with MEGA program version 3.1 (Tamura et al., 2007) based on amino acid sequence alignment. We tested the phylogenetic tree for reliability using 1000 bootstrap replications. The secondary structure was predicted using Predictprotein (http://www.predictprotein.org) software. To generate the PoCAT 3D structural model, we submitted the deduced amino acid sequence to Swiss-Model (http://swissmodel.expasy.org//SWISS-MODEL.html). The prediction was conducted in the first approach mode with default parameters (Schwede et al., 2003).

\section{Recombinant synthesis of the POAP polypeptide}

Primers (Table 1) were used to amplify PoAP, and then the PCR product was purified and ligated into the pET-32a vector (TransGen Biotech, Beijing, China). The fragment of PoAP was inserted into pET-32a at the EcoRI and HindIII site to construct pET-32a/PoAP. To obtain the recombinant protein, $\mathrm{pET}-32 \mathrm{a} / \mathrm{PoAP}$ was transformed into E. coli BL21 (TransGen Biotech, Beijing, China). The positive clones were selected and cultured in LB medium to OD600 of approximately 0.6 at $37^{\circ} \mathrm{C}$, and then induced with IPTG at a concentration of $0.1 \mathrm{mmol} / \mathrm{L}$ for $8 \mathrm{~h}$ at $18{ }^{\circ} \mathrm{C}$. In brief, the cells were harvested by centrifugation, and $10 \mathrm{ml}$ of cold lysis buffer $(50 \mathrm{mmol} / \mathrm{L} \mathrm{NaH} 2 \mathrm{PO} 4,300 \mathrm{mmol} / \mathrm{L} \mathrm{NaCl}, 20$ $\mathrm{mmol} / \mathrm{L}$ imidazole, $\mathrm{pH} 8.0$ ) containing $0.25 \mathrm{mg} / \mathrm{mL}$ lysozyme was added to the pellet and frozen at $-80^{\circ} \mathrm{C}$. After reaching $4^{\circ} \mathrm{C}$, the cells were broken by sonication for $30 \mathrm{~min}$, and the cell debris were then removed by $12,000 \mathrm{rpm}$ for $20 \mathrm{~min}$ at $4{ }^{\circ} \mathrm{C}$ centrifugation. Finally, the recombinant target protein was detected by SDS-PAGE. The concentrations of LEAP-2 were detected by Bradford assay as previously reported (Bio-Rad). Purified protein samples were separated by electrophoresis using SDS-PAGE to confirm that the purified protein band was PoAP. Then, the protein bands were transferred onto PVDF membranes (Millipore, USA) and immunoblotted with mouse anti-His monoclonal antibody (1:1000) (Sigma, USA). The detection was performed using HRP-DAB according to the manufacturer's instructions.

Table 1 Primers used in this study.

\begin{tabular}{cc}
\hline Primer name & primer sequences $\left(5^{\prime}-3^{\prime}\right)$ \\
\hline PoAP-RACE1 & TGTGAATGCCTGGTGGTCTA \\
PoAP-RACE2 & AAATGAAGATGACGCCAAGC \\
TAP & GGCCACGCGTCGACTAGTAC(T) 16 \\
AP & GGCCACGCGTCGACTAGTAC \\
PoAP-ORFF & GGTGGATCCTGGTGGTCTAAAACAGCCTCTAG \\
PoAP-ORFR & CGAAGCTTTAGTTCTTGTTATCACAAGAGAAAAGAT \\
\hline
\end{tabular}

The Israeli Journal of Aquaculture - Bamidgeh • ISSN 0792-156X • IJA.73.2021.1545208 


\section{Antibacterial activity assay}

The bacterial strains were obtained from the South China Sea Fisheries Research Institute (Guangzhou, Guangdong) and stored at $-80^{\circ} \mathrm{C}$. All tested strains were recovered and activated before each assay. The antibacterial activity was detected based on the inhibition zone method. Strains (Escherichia coli, Vibrio parahaemolyticus, Staphylococcus aureus, and Bacillus licheniformis) were inoculated on plates containing LB medium and single colonies on LB solid plates were cultured in liquid LB medium. Then, the bacterial solution was applied to the LB medium. Three Oxford cups of sterilized bacteria were collected with flame-sterilized tweezers and placed on the surface of the medium, and 50 $\mu \mathrm{L}$ of recombinant protein, pET-32a or PBS, was added.

Sequence analysis of POAP

\section{Results}

The full-length POAP cDNA contains 522 bp and consists of a 5'-UTR of 6 bp, an unusually long $3^{\prime}$-UTR of 749 bp and an open reading frame (ORF) of 375 bp that encodes a 124 amino acid peptide with a molecular weight of $13.67 \mathrm{kDa}$ and the theoretical isoelectric point of 9.25. Sequence analysis showed an RNA instability signal domain (ATTTA) in the 3'-UTR region, with a typical polyA tailing signal AATAAA, located 18 bp upstream of polyA. The deduced polypeptide includes signal peptide and mature peptide. According to the SignalP 3.0 online software, it is inferred that the cleavage site of the signal peptide is between Gla33 and Trp34, resulting in a signal peptide containing 33 amino acids. TMpred online software analyzes that PoAP has a transmembrane helical structure, between Val13 and Try35; the predicted molecular weight of the mature peptide is $0.99 \mathrm{kD}$, isoelectric point Ip9.14, containing 12 Cys structures and 13 basic amino acid residues Arg and Lys (Figure $\mathbf{1}$ ).

\section{Phylogenetic analysis of PoAP}

We used DiANNA 1.1 to predict the existence of 7 pairs of disulfide bonds in its sequence. Using Predictprotein to predict the secondary structure of PoAP protein showed that PoAP protein contains 3 segments of alpha-helix, 4 segments of a beta sheet, and the others are random coils. The alpha helix accounts for $31.5 \%$ of this sequence, and the beta-sheet ratio is $16.1 \%$ (Figure 2 ).

\section{Genomic structure analysis of POAP}

The deduced amino acid sequence of the PoAP theromacin gene was compared with theromacin sequences of other reported species (Figure 3). The protein comparison results showed that the sequence was similar to theromacin sequences of other species, such as Hyriopsis cumingii (46.8\%, ADK94899), Theromyzon tessulatum (37.1\%, AAR12065), Aplysia californica (38.7\%, ABF21076.1), and Hirudo medicinalis (29\%, ABV56207). 
1 TTC ATt ATG AAC TGT CCT CGA GTT CTT CCT GAC AGG AAA ACA GTG CAG TCA AAA TAC GTA 60 \begin{tabular}{llllllllllllllll|lllllll}
1 & & $M$ & $N$ & $C$ & $P$ & $R$ & $V$ & $L$ & $P$ & $D$ & $R$ & $K$ & $T$ & $V$ & $Q$ & $S$ & $K$ & $Y$ & $V$ & 18
\end{tabular}

61 GTA GTT GTT CTC CTA TTC ATT GTG ATG TGT CCG TAT GTG AAT GCC TGG TGG TCT AAA ACA 120

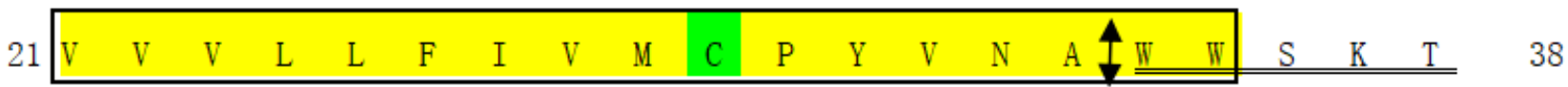

121 GCC TCT AGG TGT TTT GAC GTC TGG TCT AGA TGT TCT GGA TGG AGC CGT GCT GCT ACT GGT 180 $\begin{array}{llllllllllllllllllllllll}41 & \mathrm{~A} & \mathrm{~S} & \mathrm{R} & \mathrm{C} & \mathrm{F} & \mathrm{D} & \mathrm{V} & \mathbb{W} & \mathrm{S} & \mathrm{R} & \mathrm{C} & \mathrm{S} & \mathrm{G} & \mathbb{W} & \mathrm{S} & \mathrm{R} & \mathrm{A} & \mathrm{A} & \mathrm{T} & \mathrm{G} & & 58\end{array}$

181 TAT CTC TGG CTT AGT TGC AAC AAG TGC TGC CAA TGT AAG GGA AAA TCT GGA GGG CGT TGT 240 $\begin{array}{llllllllllllllllllllllllll}61 & \underline{Y} & \text { L } & \mathbb{W} & \mathrm{L} & \mathrm{S} & \mathrm{C} & \mathrm{N} & \mathrm{K} & \mathrm{C} & \mathrm{C} & \mathrm{Q} & \mathrm{C} & \mathrm{K} & \mathrm{G} & \mathrm{K} & \mathrm{S} & \mathrm{G} & \mathrm{G} & \mathrm{R} & \mathrm{C} & & 78\end{array}$ 241 GTA TTA GTT GCA GCG AGA GGA TGC CCC TTA TCT AAG AAT GCA TAC CAG TGT CAG TGC AAT 300 $\begin{array}{lllllllllllllllllllllllll}81 & \mathrm{~V} & \mathrm{~L} & \mathrm{~V} & \mathrm{~A} & \mathrm{~A} & \mathrm{R} & \mathrm{G} & \mathrm{C} & \mathrm{P} & \mathrm{L} & \mathrm{S} & \mathrm{K} & \mathrm{N} & \mathrm{A} & \mathrm{Y} & \mathrm{Q} & \mathrm{C} & \mathrm{Q} & \mathrm{C} & \mathrm{N} & 98\end{array}$ 301 GGG AGC AGC CTA AGG GGA GGA AAA CCG GGG TTT TGT GGT GGC AAA GCA AAT TAT CTT TTC 360

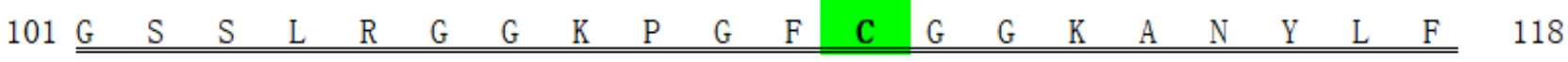
361 TCT TGT GAT AAC AAG AAC AAC AAA ATG AAG ATG ACG CCA AGC GAA ATA CGA CTG AAC 420

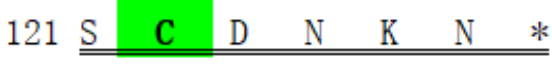

421 CGT AGA GTT GAC ATT GTC TTT ATA TTG ATG ATA ATT TCA AAT ACG GCA AAA GTC TGA TGT 480 481 ATT TAA AAT AAA AA TAT CAT TTG AAT GGC AAA AAA AAA AAA

Figure 1 Sequence of CDNA and predicted amino acid sequence of the PoAP.

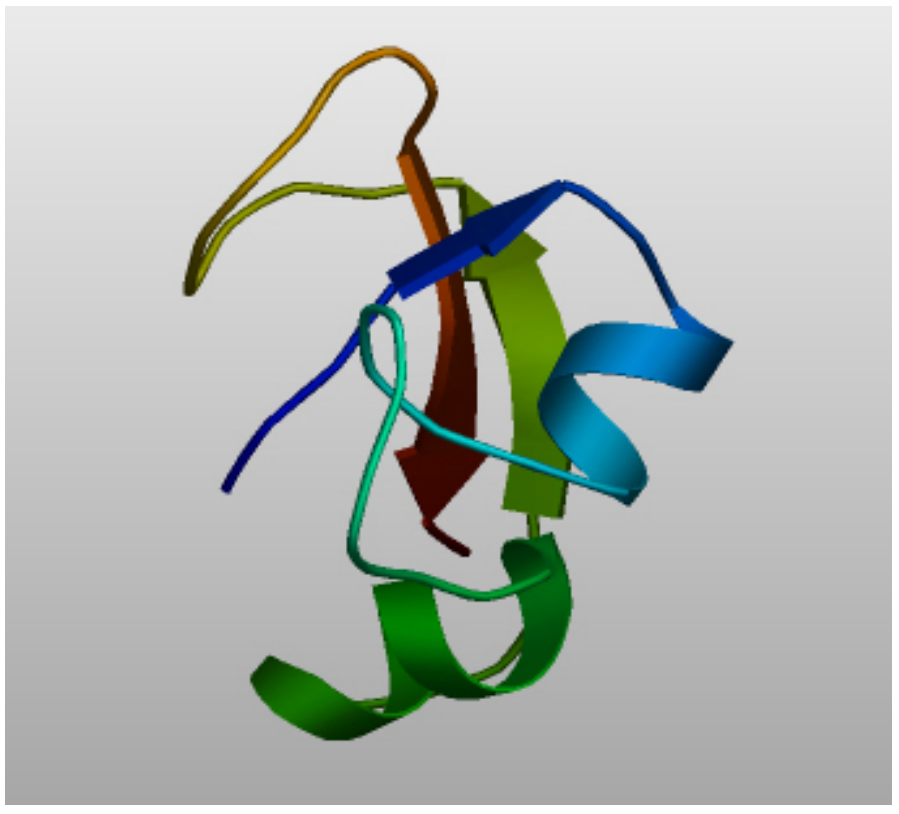

Figure 2 Three-dimensional structure model of the TOHSP9OB gene protein of PoAP. 
P. fucata

H. cumingit

A. califormica

T. tessulatum

H. medicinalis

Clustal Consensus

\section{P. fucata}

H. cumingis

A. californica

T. tessulatum

H. medicinalis

Clustal Consensus
MNCPRVLPDRKTVQSKYWWLLF IVMCP YNAIDWSKTASR FFDVWSR OSGWSRAATGYL 60 MAGINKL-------SALLWIALGYLLAP STEGF---VLSDCYDTWSRCSGWSSALTGIL 50

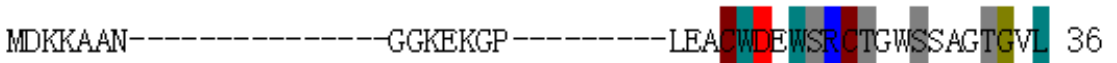

MELKSGLS----------ILLCFGICIAVIN--------AG FFEDWSR SPSTSRGTGVL 42

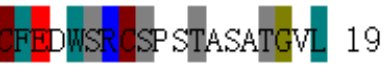

キ:: 末本枺：：牛丰 12

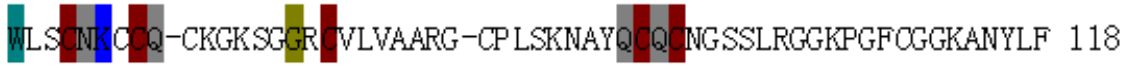
WNT TSERCQ-CLGHADGA HLAQTN-----OGEAYQCQHG-TLNGPRP------SNCKF 97 WKSDDDCH-KLGKSGGE VLTPSTCPFTRTDKAYQQGKK------------------- 76 WRDCDSYCW VCFKADRGE FDSP SLNCPQRLPNNKQCR INART AKDNR-----NP TCWA 97 WRSDSYCWVFKADRGE YDSP SLNCPHRLPNNKQ CR INART AKDNR-----NPTCWA 74

* *.. $*$ :

* * : $\quad:$ **:*

24

\section{P. fucata \\ SCDNKN 124 \\ H. Cumingit 97 \\ A. califormica \\ ------ 76 \\ T. tessulatum 97 \\ H. medicinalis 74 \\ Clustal Consensus

Figure 3 Alignment of the deduced amino acid sequences of PoAP theromacin and other theromacines.

In the phylogenetic tree, different types of antimicrobial peptides were found to be clustered singly (Figure 4). A common pedunculate theromacin was closely related to a sea rabbit belonging to an invertebrate genus, but a tripod mussel theromacin that was also a bipedal mollusk. Other different antimicrobial peptide types agglomerated and branched out from Theromacin. It indicated that the cloned PoAP gene was a theromacin type of antimicrobial peptide. 


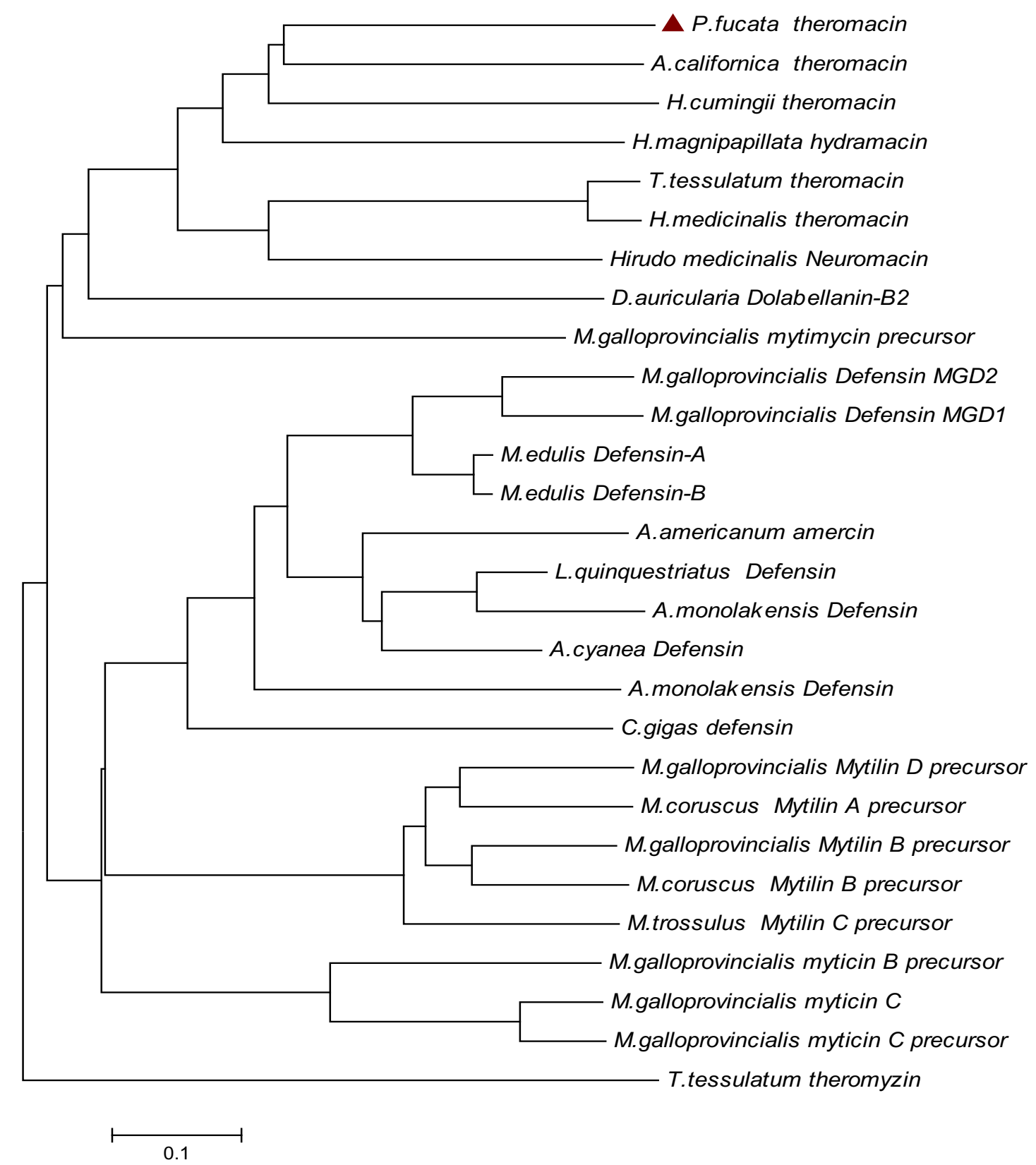

Figure 4 Neighbor-joining (NJ) phylogenetic tree constructed based on amino acid sequence encoded by the PoAP gene.

\section{Expression and purification of the recombinant POAP}

The pET32a/PoAP was about $31 \mathrm{kDa}$, consistent with the target protein size, The protein concentration measured was $12 \mathrm{mg} / \mathrm{mL}$ (Figure 5). The recombinant PoAP protein was labeled with TrXA, and Western blotting was performed to identify the target protein. As shown, the purified PoAP recombinant protein showed a $31 \mathrm{kDa}$ positive band. 


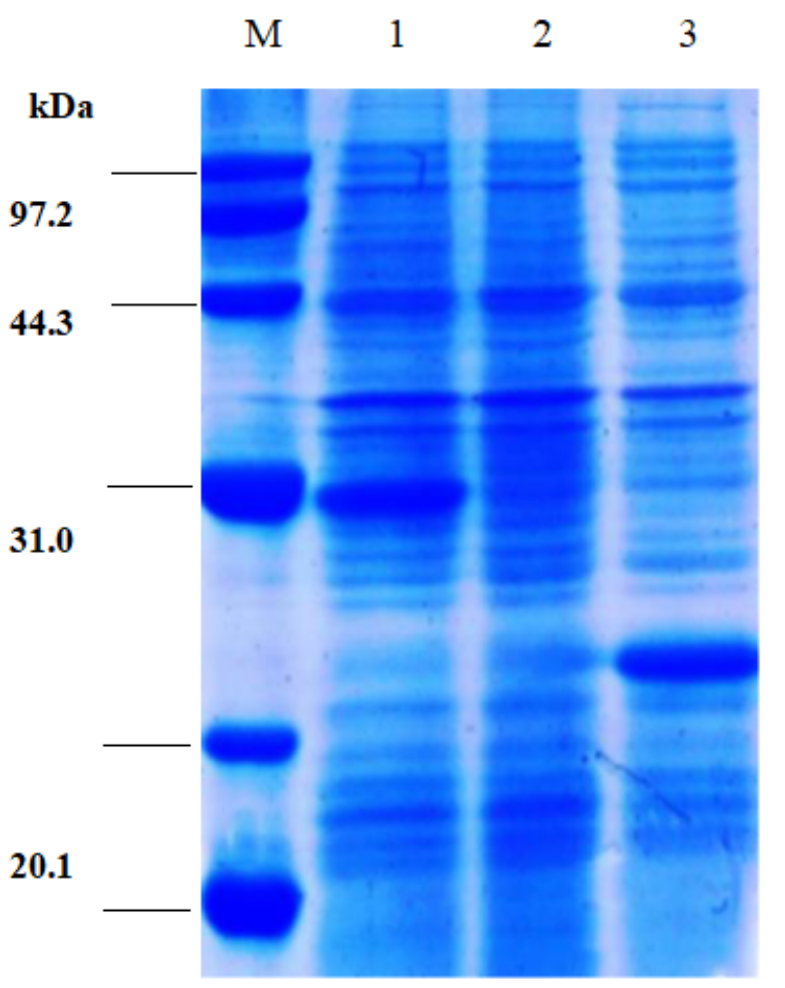

(a)

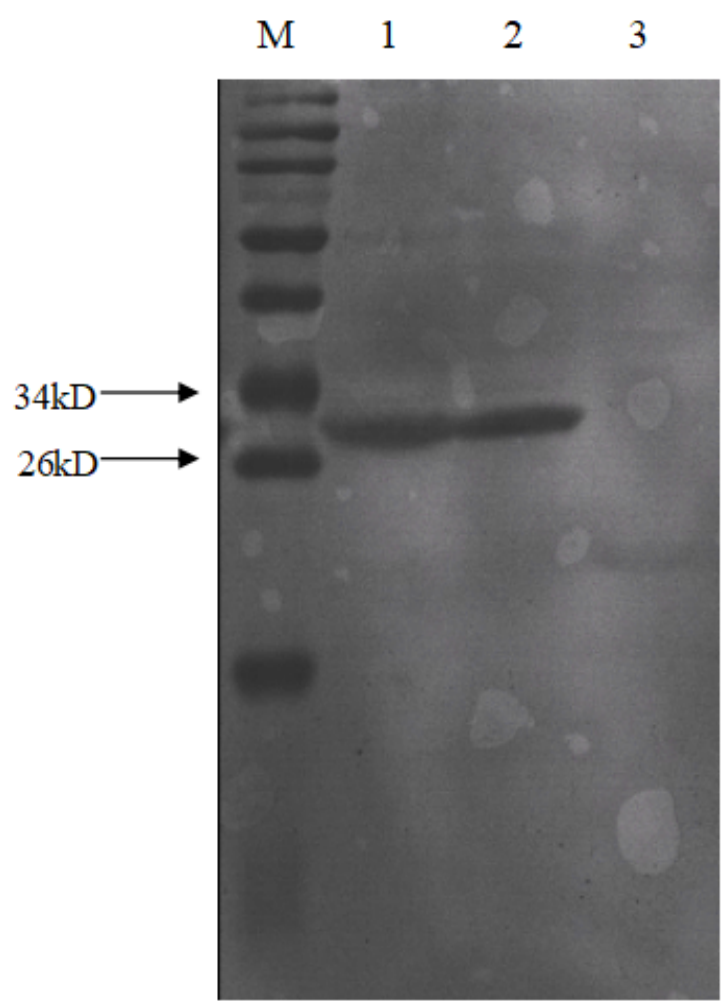

(b)

Figure 5 SDS-PAGE analysis of expression products and Western-blotting analysis (a) SDS-PAGE analysis of expression products; (b) Western-blotting analysis M:protein molecular marker; 1 :total protein of pET-32a-AP induced ;2:total protein of pET-32a-AP not induced;3:total protein of $\mathrm{pET}-32$ anot induced.

\section{Antibacterial effect of antibacterial peptides}

The agar diffusion method was used to detect the antibacterial activity of pET32a/PoAP purified protein and PBS against E. coli, V. Parahaemolyticus, S. aureus, and $B$. licheniformis. The results of its sensitivity to various tested bacteria are shown in Table 2. The results showed that the recombination of the antimicrobial peptides from Pinctada fusiformis had strong lytic activity against Gram-negative bacteria $E$. coli, and $V$. Parahaemolyticus, but had no antibacterial activity against Gram-positive bacteria $S$. aureus and $B$. licheniformis (Figure 6). This experiment shows that the antibacterial peptide-protein has selectivity in inhibiting pathogenic bacteria and is highly sensitive to gram-negative bacteria.

Table 2 The Antimicrobial spectrum of pET32a-PoAP

\begin{tabular}{lcccc}
\hline & $\begin{array}{c}\text { Escherichia } \\
\text { coli }\end{array}$ & $\begin{array}{c}\text { Staphylococcus } \\
\text { aureus }\end{array}$ & $\begin{array}{c}\text { Bacillus } \\
\text { licheniformis }\end{array}$ & \begin{tabular}{c} 
Parahaemolyticus \\
\hline pET32a-poAP
\end{tabular} \\
pET32a & + & - & - & + \\
PBS & - & - & - & - \\
\hline
\end{tabular}




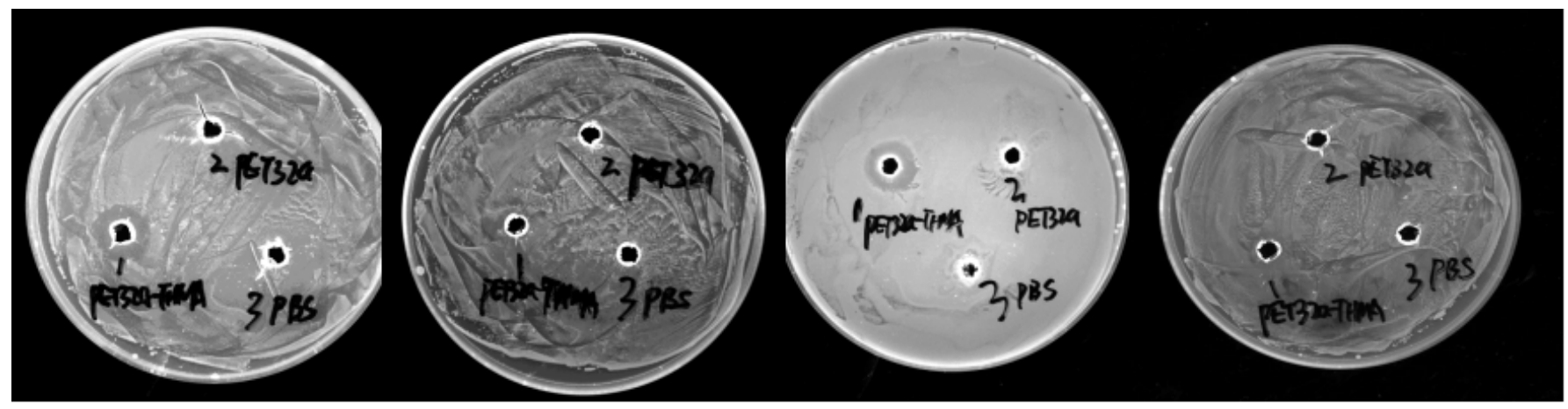

(A)

(B)

(C)

(D)

Figure 6 The antimicrobial efficiency of PoAP against different bacteria. (A) Escherichia coli, (B)

Staphylococcus aureus, (C) Vibrio Parahaemolyticus and (D) Bacillus licheniformis

\section{Discussion}

Theromacin is a class of antimicrobial peptides that have been proven to have antimicrobial effects and play an important role in the body's immune system. In this experiment, the cDNA sequence of PoAP gene obtained by analyzing the EST library is 522 bp, which comprised 5'-UTR of $6 \mathrm{bp}, 3^{\prime}$-UTR of $141 \mathrm{bp}$, an ORF of $375 \mathrm{bp}$, encode 124 amino acids, has a molecular weight of approximately $13.67 \mathrm{kDa}$ and the isoelectric point is 9.25 . The NCBI comparison found that PoAP has a high similarity with the theromacin gene of Hyriopsis cumingii and Aplysia californica, and it was speculated that the PoAP gene belongs to the antimicrobial peptide theromacin gene. The deduced polypeptide includes a signal peptide and a mature peptide. The cleavage site of the signal peptide is between Gla33 and Trp34, resulting in a signal peptide containing 33 amino acids. The predicted mature peptide has a molecular weight of $9889.4 \mathrm{D}$, an isoelectric point of Ip 9.14 , and contains 12 Cys structures and 13 basic amino acid residues Arg and Lys. The theromacin genes of other species are all found to be rich in conserved Cys residues. Hyriopsis cumingii is rich in 10 Cys residues (Xu et al., 2010), and Aplysia californica is rich in 8 Cys residues. Most types of antimicrobial peptides include Cys1-[...]-Cys2-(Xaa)3-Cys3-[...]-Gly-XaaCys4-[...]-Cys5-Xaa-Cys6 structure. Therefore, it shows that the theromacin containing 812 Cys residues is different from the conventional antimicrobial peptides containing 6 Cys residues. TMpred software predicts that PoAP gene contains a transmembrane domain, which is the same as the results of different types of antibacterial in other species.

Amino acid sequence homology analysis showed that the PoAP sequence had high similarity with other species of theromacin, such as Hyriopsis cumingii and Aplysia californica. At the same time, the results of constructing a phylogenetic tree showed that PoAP clustered with theromacin genes of other species and was closest to theromacin genes of $A$. californica, which belongs to the same invertebrate. Therefore, the PoAP gene identified can be identified as the antimicrobial peptide theromacin in this study.

As an important factor in the immune defense system of shellfish, antimicrobial peptides can eliminate and kill pathogenic microorganisms that invade the body. To better explain the diversity of antimicrobial peptides, only antimicrobial spectra were established for different antimicrobial peptide molecules. Studies have shown that Defensins and Myticin have mainly antibacterial activity against Gram-positive bacteria, including some marine invertebrate pathogenic bacteria (Hubert et al., 1996; Mitta et al., 1999). However, their activity against Gram-negative bacteria and fungi is relatively weak (Charlet et al., 1996). Mytimicin only has antibacterial activity against fungi but not against Gram-positive bacteria and Gram-negative bacteria. There are significant differences in the antibacterial activity of multiple isomers of the same type of antimicrobial peptides, such as Mytilin. 
Among them, Mytilin B, Mytilin $C$, and Mytilin D have significant antibacterial activity against Gram-positive and Gram-negative bacteria, while Mytilin G1 is only active against Gram-positive bacteria. Although the primary structures of Mytilin B and Mytilin C are highly similar, their antibacterial activities against pathogens of Fusarium, marine crustaceans, gram-negative bacteria are quite different, such as Vibrio and shellfish (Mitta et al., 2000). The study of the difference in antibacterial activity between other antibacterial peptides and their isomers is helpful to improve the comprehensive antibacterial effect of shellfish.

Our results show that $P$. fucata theromacin protein has bacteriolytic effect on Gramnegative bacteria, but not against Gram-positive bacteria. This indicates that $P$. fucata theromacin has a selective antibacterial effect on pathogenic microorganisms. Studies have found that both gram-positive bacteria and gram-negative bacteria can up-regulate the expression of the theromacin gene of $\mathrm{H}$. cumingii (Xu et al., 2010). Thus, it indicates that theromacin participates in the body's immune response process after stimulation and plays a vital role in immune defense.

\section{Acknowledgements}

Support for this work came from the National Natural Science Foundation Regional Innovation and Development Joint Fund (U20A2064), Financial Fund of Ministry of Agriculture and Rural Affairs of China (NHYYSWZZZYKZX2020), Key Special Project for Introduced Talents Team of Southern Marine Science and Engineering Guangdong Laboratory (Guangzhou) (GML2019ZD0605), the Guangdong Provincial Special Fund for Modern Agriculture Industry Technology Innovation Teams (2019KJ143), China-ASEAN maritime cooperation fund (00-201620821).

\section{References}

Altschul S.F., Madden T.L., Schaffer A.A., Zhang J., Zhang Z., Miller W., Lipman D.J., 1997. Gapped BLAST and PSI-BLAST: a new generation of protein database search programs. Nucleic Acids Res. 25, 3389-3402. https://doi.org/10.1093/nar/25.17.3389

Campanella J.J., Bitincka L., Smalley J., 2003. MatGat: an application that generates similarity/identity matrices using protein or DNA sequences. BMC Bioinformatics 4,1-4. https://doi.org/10.1186/1471-2105-4-29

Charlet M., Chernysh S., Philippe H., Hetru C., Hoffmann J.A., Bulet P., 1996. Innate immunity. Isolation of several cysteine-rich antimicrobial peptides from the blood of a mollusc, Mytilus edulis. J. Biol. Chem. 1996, 271, 21808-21813. https://doi.org/10.1074/jbc.271.36.21808

Hubert F., Noel T., Roch P.A., 1996. A member of the arthropod defensin family from edible Mediterranean mussels (Mytilus galloprovincialis). Eur. J. Biochem, 1996.,240, 302306. https://doi.org/10.1111/j.1432-1033.1996.0302h.x

Jung S, Dingley AJ, Augustin R, Gelhaus C., Bosch T., Podschun R., Leippe M., Grtzinger J., 2009. Hydramacin1, structure and antibacterial activity of a protein from the basal metazoan Hydra. J Biol Chem, 284(3): 1896-1905. https://doi.org/10.1074/jbc.M804713200

Letunic I., Copley R.P., Pils B., Pinkert S., Schultz J., Bork P., 2006. SMART 5: domains in the context of genomes and networks. Nucleic Acids Res. 34, 257-260. https://doi.org/10.1093/nar/gkj079

Loker ES, Adema CM, Zhang SM, Kepler T.B., 2010. Invertebrate Immune Systems-Not Homogeneous, Not Simple, Not Well Understood. Immunol Rev, 2010, 198(1): 10-24. https://doi.org/10.4103/0250-474X.62229

Marco G, Gianluca DM, Manfrin C, Venier P., Pallavicini A., 2012. Big defensins and mytimacins, new AMP families of the Mediter-ranean mussel Mytilus galloprovincialis. Dev Comp Immunol, 2012, 36(2): 390-399. https://doi.org/10.1016/j.dci.2011.08.003

Mitta G, Hubert F, Noël T., Roch P., 1999. Myticin, a novel cysteine- rich antimicrobial peptide isolated from haemocytes and plasma of the mussel Mytilus galloprovincialis. 
European Journal of Biochemistry, 265(1):71-78. https://doi.org/10.1046/j.14321327.1999.00654.x

Mitta G., Vandenbulcke F., Hubert F., Salzet M., Roch P., 2000. Involvement of mytilins in mussel antimicrobial defense. J. Biol. Chem, 275, 12954-12962. https://doi.org/10.1074/jbc.275.17.12954

Schikorski D, Cuvillier-Hot V, Leippe M, Boidin-Wichlacz C., Slomianny C., Macagno E., Salzet M., Tasiemski A., 2008. Microbial challenge promotes the regenerative process of the injured central nervous system of the medicinal leech by inducing the synthesis of antimicrobial peptides in neurons and microglia. J Immunol, 2008, 181(2): 1083-1095. https://doi.org/10.4049/jimmunol.181.2.1083

Schwede T., Kopp J., Guex N., Peitsch M.C., 2003. SWISS-MODEL: an automated protein homology-modeling server. Nucleic Acids Res. 31, 3381-3385. https://doi.org/10.1093/nar/gkg520

Sascha J, Frank DS, Chien H, Andreas T., Céline B.W., Wiebke H., Christoph G., Christine D., Rainer P., Vicki W., Aurélie T., Matthias L., Joachim G., 2012. Macin Family of Antimicrobial Proteins Combines Antimicrobial and Nerve Repair Activities. J Biol Chem, 2012, 287(17): 14246-14258. https://doi.org/10.1074/jbc.M111.336495

Tasiemski A, Vandenbulcke F, Mitta G, Lemoine J., Lefebvre C., Sautière P.E., Salzet M., 2004. Molecular characterization of two novel antibacterial peptides inducible upon bacterial challenge in an annelid, the leech Theromyzon tessulatum. J Biol Chem, 279(30): 30973-30978. https://doi.org/10.1074/jbc.M312156200

Tamura K., Dudley J., Nei M., Kumar, 2007. MEGA4: Molecular Evolutionary Genetics Analysis (MEGA) software version 4.0. Mol. Biol. Evol. 24, 1596-1599. https://doi.org/10.1093/molbev/msm092

Wang Q, Yuan Z, Wu H, Liu F., Zhao J.M., 2013a. Molecular Characterization of a Manganese Superoxide Dismutase and Copper/Zinc Superoxide Dismutase from the mussel Mytilus galloprovincialis. Fish Shellfish Immunol, 34(5): 1345-1351. https://doi.org/10.1016/j.fsi.2013.01.011

Wang LL, Qiu LM, Zhi Z, Song L.S., 2013b. Research Progress on the Mollusc Immunity in China. Dev Comp Immunol, 39(1-2): 2-10. https://doi.org/10.1016/j.dci.2012.06.014

Xu QQ, Wang GL, Yuan HW, Chai Y, Xiao ZL., 2010. CDNA sequence and expression analysis of an antimicrobial peptide, theromacin, in the triangle-shell pearl mussel Hyriopsis cumingii. Comp Biochem Physiol $B, \quad 157:$ 119-126. https://doi.org/10.1016/j.cbpb.2010.05.010 